\title{
Reduction of pulmonary toxicity of metal oxide nanoparticles by phosphonate-based surface passivation
}

Xiaoming $\mathrm{Cai}^{1 \dagger}$, Anson Lee ${ }^{5+}$, Zhaoxia $\mathrm{Ji}^{4}$, Cynthia Huang ${ }^{6}$, Chong Hyun Chang ${ }^{4}$, Xiang Wang ${ }^{4}$, Yu-Pei Liao ${ }^{3}$, Tian $\mathrm{Xia}^{3,4^{*}}$ and Ruibin $\mathrm{Li}^{2^{*}}$ (D)

\begin{abstract}
Background: The wide application of engineered nanoparticles has induced increasing exposure to humans and environment, which led to substantial concerns on their biosafety. Some metal oxides (MOx) have shown severe toxicity in cells and animals, thus safe designs of MOx with reduced hazard potential are desired. Currently, there is a lack of a simple yet effective safe design approach for the toxic MOx. In this study, we determined the key physicochemical properties of MOx that lead to cytotoxicity and explored a safe design approach for toxic MOx by modifying their hazard properties.
\end{abstract}

Results: THP-1 and BEAS-2B cells were exposed to $0-200 \mu \mathrm{g} / \mathrm{mL}$ MOx for $24 \mathrm{~h}$, we found some toxic MOx including $\mathrm{CoO}, \mathrm{CuO}, \mathrm{Ni}_{2} \mathrm{O}_{3}$ and $\mathrm{CO}_{3} \mathrm{O}_{4}$, could induce reactive oxygen species (ROS) generation and cell death due to the toxic ion shedding and/or oxidative stress generation from the active surface of MOx internalized into lysosomes. We thus hypothesized that surface passivation could reduce or eliminate the toxicity of MOx. We experimented with a series of surface coating molecules and discovered that ethylenediamine tetra (methylene phosphonic acid) (EDTMP) could form stable hexadentate coordination with MOx. The coating layer can effectively reduce the surface activity of $\mathrm{MOx}$ with $85-99 \%$ decrease of oxidative potential, and $65-98 \%$ decrease of ion shedding. The EDTMP coated MOx show negligible ROS generation and cell death in THP-1 and BEAS-2B cells. The protective effect of EDTMP coating was further validated in mouse lungs exposed to $2 \mathrm{mg} / \mathrm{kg} \mathrm{MOx}$ by oropharyngeal aspiration. After $40 \mathrm{~h}$ exposure, EDTMP coated MOx show significant decreases of neutrophil counts, lactate dehydrogenase (LDH) release, MCP-1, LIX and IL-6 in bronchoalveolar lavage fluid (BALF), compared to uncoated particles. The haematoxylin and eosin (H\&E) staining results of lung tissue also show EDTMP coating could significantly reduce the pulmonary inflammation of MOX.

Conclusions: The surface reactivity of MOx including ion shedding and oxidative potential is the dominated physicochemical property that is responsible for the cytotoxicity induced by MOx. EDTMP coating could passivate the surface of MOx, reduce their cytotoxicity and pulmonary hazard effects. This coating would be an effective safe design approach for a broad spectrum of toxic MOx, which will facilitate the safe use of MOx in commercial nanoproducts.

Keywords: Metal oxides, Nanotoxicity, Functionalization, Lung toxicity, Surface coating, Inhalation, Inflammation

\footnotetext{
* Correspondence: txia@ucla.edu; liruibin@suda.edu.cn

${ }^{\dagger}$ Equal contributors

${ }^{3}$ Department of Medicine, University of California, Los Angeles, California 90095, USA

${ }^{2}$ School for Radiological and Interdisciplinary Sciences (RAD-X), Collaborative

Innovation Center of Radiation Medicine of Jiangsu Higher Education

Institutions, Jiangsu Provincial Key Laboratory of Radiation Medicine and

Protection, Soochow University, Suzhou 215123, China

Full list of author information is available at the end of the article
} 


\section{Background}

Metal oxides (MOx) are the most produced nanomaterials because of their unique physicochemical properties including catalytic activity, antibacterial capability, chemical stability, electrical, thermal and mechanical characteristics. MOx are now widely used in electronics, mechanics, biomedicine, catalysis, cosmetics, painting, polishing, etc. [1-3]. The increasing production as well as wide use of MOx has led to substantial concerns on their potential hazardous effects to both humans and environment [4]. Some MOx have been reported to induce reactive oxygen species (ROS) generation [5], mitochondrial damage [6], cytochrome $C$ release [7], DNA damage [8], inflammatory cytokine release [9-11] and cell death[12]. After exposure to animal lungs, certain $\mathrm{MOx}$ can trigger acute pulmonary inflammation [13]. In addition, other hazardous effects including autophagy interferences and pro-fibrogenic effects were also reported $[11,14]$. The toxicity induced by $\mathrm{MOx}$ has been demonstrated to closely correlate with their surface properties such as electronic property (band gap), functional groups, dissolution, etc. [10, 13, 15]. Therefore, we hypothesized that surface passivation could be an effective approach to engineer safe MOx.

Currently, safe design approaches including surface coating [16, 17], core-shell structure [18, 19], doping [20] and geometric control [21] have been developed to reduce the hazard effects of nanomaterials. Among these safe design approaches, surface coating is a simple and effective post-modification method, which can be extended to a variety of nanoparticles with similar surface properties. For example, Wang et al. found that pluronic molecules can effectively reduce the hazard potential of carbon nanotubes [22], and this coating approach could be extended to protect other carbonaceous nanomaterials including graphene and graphene oxide [23] or other 2-D materials such as $\mathrm{MoS}_{2}$ [24]. Since MOx induced toxicity are mainly based on surface reactivity or ion shedding from MOx surface, surface coating would have the opportunity to reduce both. However, to date, there is lack of an effective surface coating approach for a broad-spectrum of MOx.

In this communication, we experimented with a series of coating molecules on selected MOx to discover the most effective for surface passivation. The desired coating molecule could reduce the surface reactivity and/or dissolution of MOx, and thus reduce the hazard potential of MOx in vitro and in vivo.

\section{Methods}

\section{Materials}

$\mathrm{CoO}$ and $\mathrm{Ni}_{2} \mathrm{O}_{3}$ nanoparticles were purchased from SkySpring Nanomaterials (Houston, TX); $\mathrm{CuO}, \mathrm{Co}_{3} \mathrm{O}_{4}$ and $\mathrm{TiO}_{2}$ nanoparticles were synthesized by a flame spray pyrolysis reactor; Ethylenediamine tetra(methylenephosphonic acid) (EDTMP) was purchased from Tokyo Chemical Industry Co. (Chuo-ku, Tokyo, Japan); poly(vinylpyrrolidone) (PVP) and citrate were purchased from Sigma-Aldrich (St. Louis, MO). ELISA kits for detection of IL-6 and MCP-1, purchased from BD Biosciences (San Jose, CA). LIX ELISA kit was purchased from R\&D Systems (Minneapolis, MN). Hoechst 33342 were purchased from Life Technologies (Grand Island, NY, USA). The lactate dehydrogenase (LDH) and MTS assay kits were obtained from Promega (Madison, WI) ATP assay kit was purchased from PerkinElmer (Boston, MA).

\section{Nanoparticle Characterization}

All of the nanoparticles were provided in powder form. Transmission electron microscopy (TEM, JEOL 1200 EX instrument) was used to observe the shapes and primary sizes of the nanoparticles. Samples were prepared by placing a drop of the aqueous nanoparticle suspension on a carbon-coated TEM grid and waiting until the water evaporates. To determine the primary particle size, 100 nanoparticles were counted in the TEM images of each MOx. Dynamic light scattering (DLS, Dynapro Plate Reader, Wyatt Technology) was performed to determine the particle size in water and the cell culture media. Zeta-potential measurement of the nanoparticle suspensions was performed using a ZetaPALS instrument (Zeta Potential Analyzer, Brookhaven Instruments Corporation, Holtsville, NY). Metal dissolution was determined by inductively coupled plasma optical emission spectrometry (ICP-OES) (ICPE-9000, Shimadzu, Japan). Fourier transform infrared (FTIR) spectra were collected using a Bruker Vertex 70 instrument.

\section{Confocal Microscopy Imaging}

For cellular biodistribution study, THP-1 cells were incubated with $25 \mu \mathrm{g} / \mathrm{mL}$ FITC labeled $\mathrm{TiO}_{2}, \mathrm{Co}_{3} \mathrm{O}_{4}$ and $\mathrm{CuO}$ nanoparticle suspensions for $16 \mathrm{~h}$. For intracellular ROS visualization, MitoSOX ${ }^{\mathrm{m}}$ reagent (Invitrogen, USA) was diluted in cell culture media at $5 \mu \mathrm{M}$ and applied to cells pretreated with $100 \mu \mathrm{g} / \mathrm{mL}$ coated or uncoated MOx for $16 \mathrm{~h}$, followed by $10 \mathrm{~min}$ incubation at $37{ }^{\circ} \mathrm{C}$. Then the cells were collected and washed with PBS for 3 times. After fixing in 4\% paraformaldehyde, cells were stained with Hoechst 33342 or Alexa Fluor 594 labeled anti-LAMP1 to visualize the nuclei and lysosomes, respectively, by Leica confocal SP2 1P/FCS microscope.

\section{Surface coating}

We compared the coating efficiency of coating molecules (citrate, PVP, EDTMP, Aminomethyl phosphonic acid, Polyethylene glycol, 3-bromopropyl phosphonic acid, etc.) 
at a $0.5 \sim 5$ weight ratio of coating agent $v s \mathrm{MOx}$, and found that a weight ratio of 2 was sufficient for effective surface passivation. Therefore, a $2 \mathrm{mg}$ amount of $\mathrm{MOx}$ was dispersed in $10 \mathrm{~mL}$ of $\mathrm{DI} \mathrm{H}_{2} \mathrm{O}$ containing coating molecules at concentration of $400 \mu \mathrm{g} / \mathrm{mL}$. MOx were reacted with these coating molecules for $24 \mathrm{~h}$ at room temperature with magnetic stirring. The particle solutions were centrifuged at $135,558 \mathrm{~g} / \mathrm{min}$ for $1 \mathrm{~h}$ to collect the particle pellets. After washing with DI $\mathrm{H}_{2} \mathrm{O}$, the coated $\mathrm{MOx}$ were stored at $4{ }^{\circ} \mathrm{C}$ for further characterization and use.

\section{Preparation of MO nanoparticle suspensions in media}

Coated and uncoated metal oxide nanoparticles were suspended in DI water at $5 \mathrm{mg} / \mathrm{mL}$ as stock solutions. These suspensions were sonicated at $100 \mathrm{~W}$ output with frequency of $42 \mathrm{kHz}$ for $15 \mathrm{~min}$ in a water sonicator (Branson, Danbury, CT, USA, model 2510). The suspensions were used as stock solutions for further dispersion in cell culture media or PBS. An appropriate amount of each stock solution was added to cell culture media or PBS to achieve the desired final concentration. For better dispersion, BSA was added to BEGM medium or PBS at $0.2 \mathrm{mg} / \mathrm{mL}$, before the addition of nanoparticles. The diluted MO suspensions were dispersed using a sonication probe (Sonics \& Materials, USA) at $32 \mathrm{~W}$ for $10 \mathrm{~s}$ at the desired final concentration before further use.

\section{Assessment of the oxidative capability of MOx}

The oxidative capacity of MOx were determined by a method as described before [15]. 2,7'-dichlorodihydrofluorescein diacetate $\left(\mathrm{H}_{2} \mathrm{DCFDA}\right)$ was used to evaluate the oxidation capacity of MOx. The 2',7'-dichlorofluorescein (DCF) working solution was prepared by mixing $50 \mu \mathrm{g}$ of $\mathrm{H}_{2}$ DCFDA with $280 \mu \mathrm{L} 0.01 \mathrm{M} \mathrm{NaOH}$. The resulting solution was incubated for $30 \mathrm{~min}$, and diluted with $1720 \mu \mathrm{L}$ of a sodium phosphate buffer $(25 \mathrm{mmol} / \mathrm{L}$, $\mathrm{pH}=7.4$ ) to form $25 \mu \mathrm{g} / \mathrm{mL}$ DCF solution. $96 \mu \mathrm{L}$ aliquots of $25 \mu \mathrm{g} / \mathrm{mL}$ DCF working solutions were added into each well of a 96 multiwell black plate (Costar, Corning, NY). A $4 \mu \mathrm{L}$ amount of $5 \mathrm{mg} / \mathrm{mL}$ nanoparticle suspension was subsequently added to each well, followed by $2 \mathrm{~h}$ incubation. DCF fluorescence emission spectra in the range of 500-600 nm were collected using a SpectraMax M5 microplate reader with an excitation wavelength of $490 \mathrm{~nm}$.

\section{Cell viability test}

BEAS-2B and THP-1 cells were obtained from ATCC (Manassas, VA, USA). BEAS-2B cells were suspended in BEGM medium at a density of $1 \times 10^{5} / \mathrm{mL}$, and then added in 96-well plates with $100 \mu \mathrm{L} /$ well. Aliquots of $3 \times 10^{4}$ THP- 1 cells were seeded in $0.1 \mathrm{~mL}$ RPMI 1640 complemented with $1 \mu \mathrm{g} / \mathrm{mL}$ phorbol 12-myristate acetate
(PMA) in 96-well plates (Corning, NY, USA). After overnight incubation at $37^{\circ} \mathrm{C}$, the culture media were replaced with MO suspensions in BEGM or RPMI 1640 media at concentrations ranging from 0 to $200 \mu \mathrm{g} / \mathrm{mL}$, followed by $24 \mathrm{~h}$ incubation. Then the ATP or MTS assay solutions were added to evaluate cell viabilities by measuring the luminescence or absorbance on a SpectraMax M5 microplate spectrophotometer.

\section{Assessment of acute toxicological responses in the mouse lung}

Male C57Bl/6 mice (8 weeks old) from Charles River Laboratories (Hollister, CA, USA) were used to test the coated and uncoated MOx. The animals were housed in a standard laboratory conditions by UCLA guidelines as well as the NIH Guide for the Care and Use of Laboratory Animals (DHEW78-23). Mice were exposed to $2 \mathrm{mg} / \mathrm{kg} \mathrm{MOx}$ by oropharyngeal aspiration procedure as described before [10]. In detail, a total volume of $100 \mu \mathrm{L}$ ketamine $(100 \mathrm{mg} / \mathrm{kg}) /$ xylazine $(10 \mathrm{mg} / \mathrm{kg})$ was intraperitoneally injected to anesthetize the animals. The anesthetized animals were held in a vertical position to instill $50 \mu \mathrm{L}$ PBS suspension containing $50 \mu \mathrm{g}$ nanoparticles at the back of the tongue to allow pulmonary aspiration. Then the animals were placed to lay on their backs for recovery. The positive control group in each experiment received $5 \mathrm{mg} / \mathrm{kg}$ crystalline silica in the form of quartz particles (Min-U-Sil). After $40 \mathrm{~h}$ exposure, animals were sacrificed to collect bronchoalveolar lavage fluid (BALF) and lung tissues. IL-6, MCP-1 and LIX productions were measured in the BALF by ELISA. $\mathrm{LDH}$ level in BALF was determined by CytoTox $96^{\circ}$ Non-Radioactive Cytotoxicity Assay kit form Promega (Madison, WI, USA) Lung tissue was fixed and stained with haematoxylin and eosin (H\&E) to examine inflammations.

\section{Statistical Methods}

Mean and standard deviation (SD) were calculated for each parameter. Results were expressed as mean SD of multiple determinations. Comparisons between groups were evaluated by two-side Student's t-test or one-way ANOVA. A statistically significant difference was assumed to exist when $\mathrm{p}$ was $<0.05$.

\section{Results}

Characterizing the surface reactivity of MOx and determining their cytotoxicity

First, we established a library of $\mathrm{MOx}$ including $\mathrm{CoO}$, $\mathrm{Ni}_{2} \mathrm{O}_{3}, \mathrm{Co}_{3} \mathrm{O}_{4}, \mathrm{CuO}$, which have been shown to induce cell death by oxidative stress mechanism, and $\mathrm{TiO}_{2}$ was used as negative control. The shape, size and surface charge of these nanoparticles were characterized by TEM, DLS and zeta-potential analysis. As shown in Fig. 1a, 
A

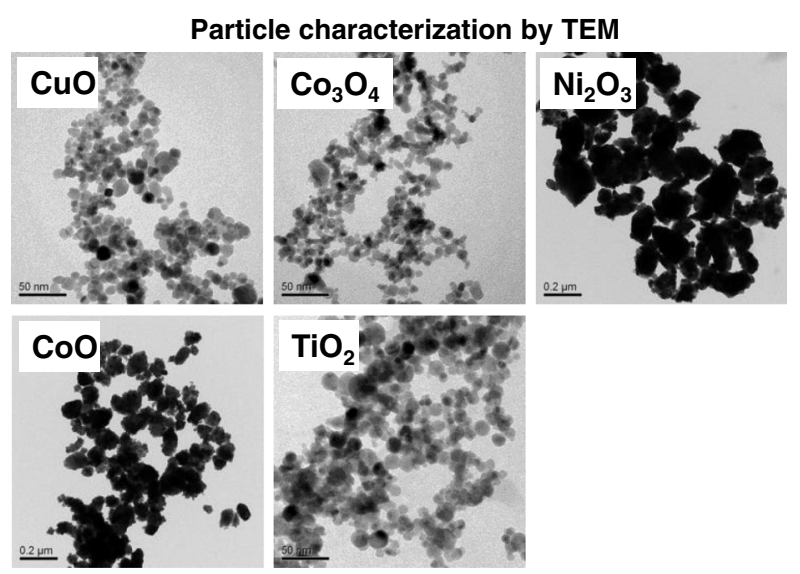

B

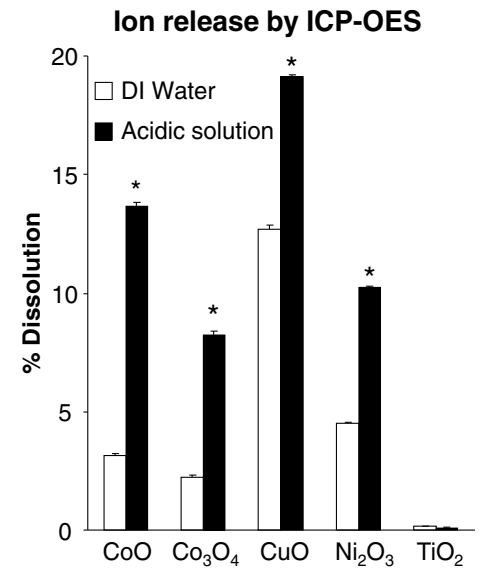

\section{Oxidative stress by DCF assay}
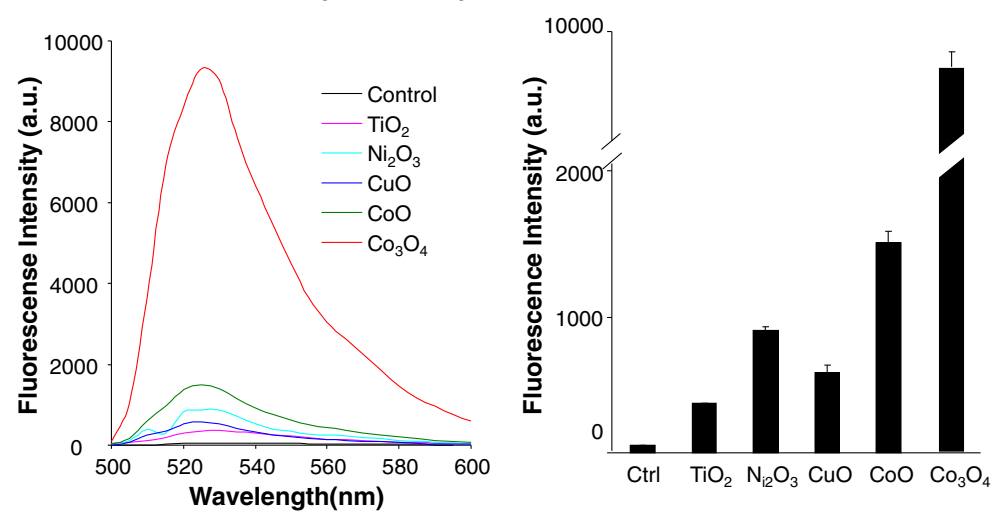

Fig. 1 Characterizing the physicochemical properties of MO nanoparticles. a TEM images showing the shape and size of MOx, $\mathbf{b}$ Dissolution percentage of MO NPs in DI water and acidic solution, and $\mathbf{c}$ Determining the oxidative capability of MOx by DCF assay. The dissolution analysis was performed by suspending $50 \mathrm{\mu g} / \mathrm{mL}$ of each of the nanoparticles in deionized water or acidic solution ( $\mathrm{pH}$ 4.5, HCl), followed by incubation at room temperature for $24 \mathrm{~h}$. The supernatants were collected by centrifugation at $20000 \mathrm{~g}$ for $30 \mathrm{~min}$ and digested for ICP-OES measurement. For DCF assay, $200 \mu \mathrm{g} / \mathrm{mL}$ MOx suspensions were incubated with DCF solutions at $25 \mu \mathrm{g} / \mathrm{mL}$ for $2 \mathrm{~h}$. The fluorescence emission spectra of the mixed solutions were collected at 500-600 nm with excitation at $490 \mathrm{~nm} .{ }^{*} p<0.05$ compared to the ion release in water

primary particle sizes, as determined by TEM, are in the range of 10-100 $\mathrm{nm}$. The hydrodynamic sizes assessed by DLS in water, as well as BEGM and RPMI tissue culture media, show a range from 200 to $600 \mathrm{~nm}$, indicating that
MOx tend to agglomerate in media (Additional file 1: Table S1). These particles show very similar zeta potential at 5 to $-10 \mathrm{mV}$ in cell culture media, which reflects the formation of protein corona on particle surface. 
Since the mechanism of MO-induced toxicity may involve oxidative stress that can be linked to surface reactivity (e.g., band gap) or dissolution, we determined the dissolution rate and ability to generate ROS by MOx. Because MOx are mainly internalized into acidic lysosomes in cells (Additional file 2: Figure S1), we studied the dissolution rate of MOx in deionized water and acidic solution $(\mathrm{HCl}, \mathrm{pH} 4.5)$, which has same $\mathrm{pH}$ but less component-complexity to artificial lysosomal fluids [25]. The released metal ions were detected by ICP-OES. As shown in Fig. 1b, compared to the dissolution rate in deionized water, $\mathrm{CoO}, \mathrm{Co}_{3} \mathrm{O}_{4}, \mathrm{CuO}$ and $\mathrm{Ni}_{2} \mathrm{O}_{3}$ have significantly increased metal ion release at $\mathrm{pH} 4.5$, while $\mathrm{TiO}_{2}$ is very stable in both deionized water and acidic solutions. $\mathrm{CuO}$ is the most dissoluble particle (19.11\%) in acidic solution, while the dissolution of $\mathrm{Co}_{3} \mathrm{O}_{4}(8.23 \%)$ is relatively low compared to $\mathrm{CuO}, \mathrm{Ni}_{2} \mathrm{O}_{3}(10.23 \%)$ and $\mathrm{CoO}(13.65 \%)$.

We used DCF assay to investigate the oxidative potential of MOx. The DCF assay is based on a mechanism that nonfluorescent $\mathrm{H}_{2}$ DCFDA could be converted to the highly fluorescent DCF by oxidation. This assay has been widely used to access the abiotic ROS generation on nanoparticle surface [15]. As shown in Fig. 1c, while $\mathrm{TiO}_{2}$ and $\mathrm{CuO}$ show very limited oxidative potential, $\mathrm{Ni}_{2} \mathrm{O}_{3}$ and $\mathrm{CoO}$ induce substantial increases in ROS generation and $\mathrm{Co}_{3} \mathrm{O}_{4}$ exhibits the highest level.

Shedding of toxic ions or ROS generation could lead to cytotoxicity. We examined cell viability in THP-1 and BEAS-2B cells by MTS and ATP assays to measure the cellular metabolic activity. The results showed that $\mathrm{CoO}$, $\mathrm{Ni}_{2} \mathrm{O}_{3}, \mathrm{Co}_{3} \mathrm{O}_{4}$ and $\mathrm{CuO}$ induced significant cell death in THP-1 and BEAS-2B cells, while $\mathrm{TiO}_{2}$ has no effect in cell viability (Fig. 2 and Additional file 3: Figure S2). These results are consistent with previous reports that used RAW 264.7, A549 and HeLa cells [26-28]. The cytotoxicity of MOx has good correlation with the surface activity or dissolution of MOx, which are the key physicochemical properties that induce cell death.

\section{Engineering safe coating approach for $\mathrm{CuO}$ nanoparticles} In order to lower the cytotoxicity induced by MOx, we screened a series of coating agents. Herein, we compared the cytotoxicity of uncoated $\mathrm{CuO}$ and coated $\mathrm{CuO}$ by citrate, PVP and EDTMP to evaluate the effect of these coating agents. As shown in Additional file 4: Figure S3, citrate shows very limited protective effect, PVP has a moderate effect, while EDTMP is the most effective.

We characterize the EDTMP coated CuO (EDTMP$\mathrm{CuO}$ ) by FTIR, TEM and XRD to understand the interaction between EDTMP molecules and CuO NPs. As shown in Additional file 5: Figure S4A, we compared the spectra of EDTMP, EDTMP-CuO and $\mathrm{CuO}$. $\mathrm{CuO}$ particles show signature peaks of $\mathrm{Cu}-\mathrm{O}$ stretching at 529 and $591 \mathrm{~cm}^{-1}$ bands [29]. The absorption peaks at $1626 \mathrm{~cm}^{-1}$ and $3443 \mathrm{~cm}^{-1}$ bands could be attributed to the bending vibration of hydroxyl groups or some carbonate on the surface of $\mathrm{CuO}$ [29]. After EDTMP coating, the intensities of $-\mathrm{OH}$ and carbonate peaks have a significant decrease. The additional peaks at $1109 \mathrm{~cm}^{-1}$ and $1048 \mathrm{~cm}^{-1}$ from EDTMP-CuO could be attributed to the symmetric and antisymmetric phosphonate stretching vibrations of EDTMP [30]. The XRD analysis shows that EDTMP coating does not change the crystal structure of $\mathrm{CuO}$ (Additional file 5: Figure S4B). Both coated and uncoated particles have similar morphology (Additional file 5: Figure S4C). The schematic in Fig. $3 \mathrm{a}$ shows the predicted structure of the EDTMP-Cu conjugate. The organophosphate ligand coordinates to the metal atoms in a hexadentate fashion, involving two nitrogen and four oxygen atoms. The tetrahedral phosphonic groups in this complex limit the free space around the
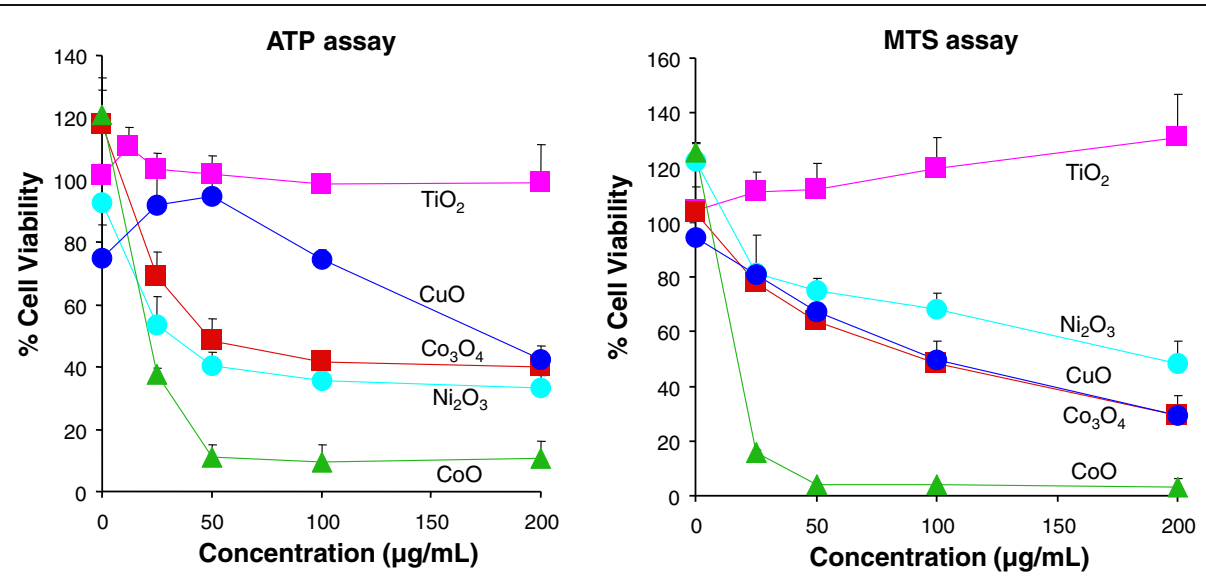

Fig. 2 Assessment of Cell viability in BEAS-2B cells exposed to MOx. Cell viability tests were performed by ATP (left panel) MTS (right panel) assays. BEAS-2B cells were exposed to MOx suspensions $(0-200 \mu \mathrm{g} / \mathrm{mL}$ ) for $24 \mathrm{~h}$. Then the MTS or ATP assay solutions were added to evaluate cell viabilities by measuring the absorbance or luminescence on a SpectraMax M5 microplate spectrophotometer 
A

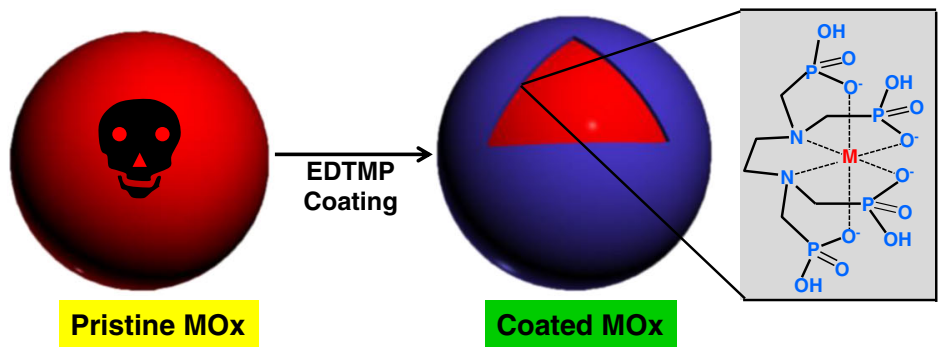

B
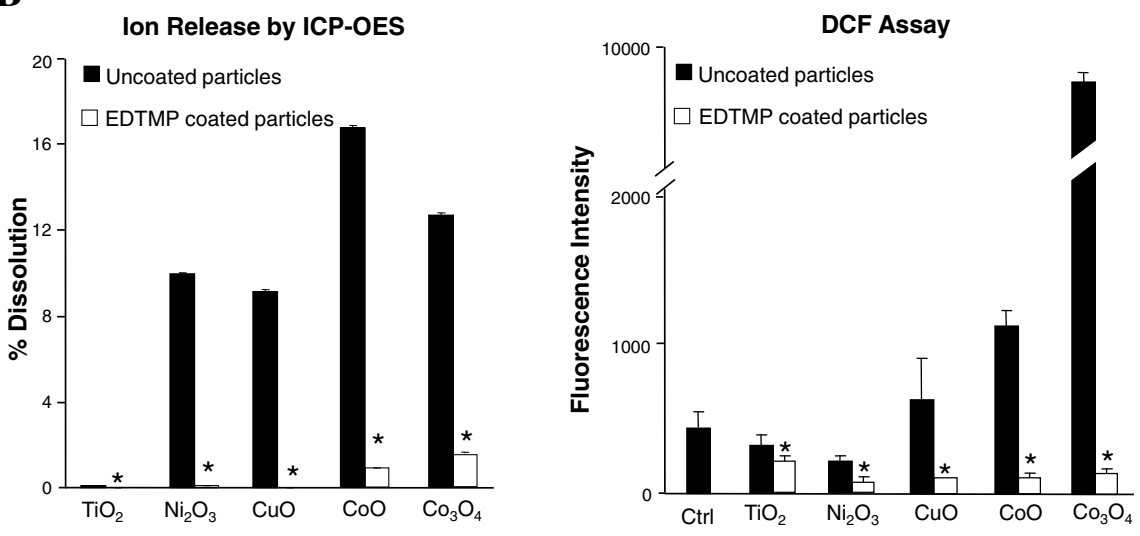

C

ROS detection by Mitosox staining
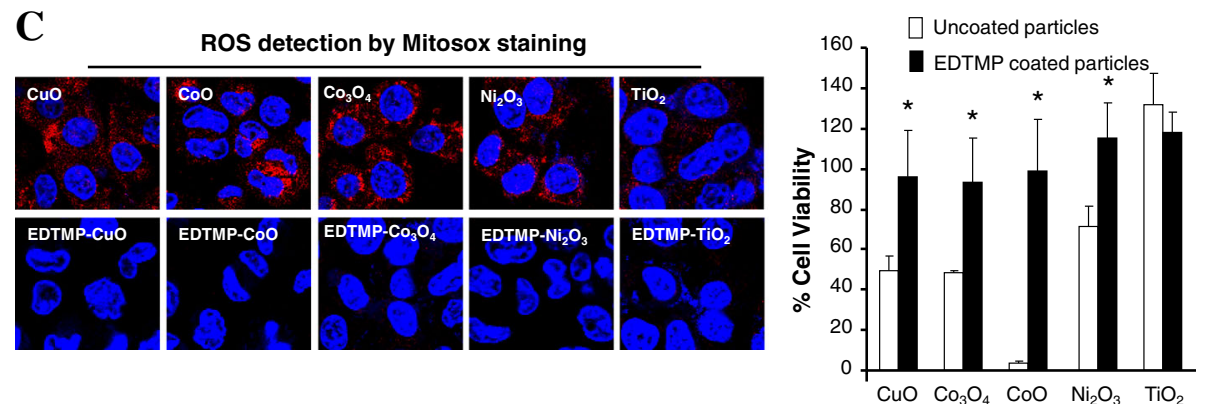

Fig. 3 Safe design of MOx by surface passivation. a Formation of EDTMP-metal conjugate on MOx surface, $\mathbf{b}$ lon release and oxidative capability of uncoated and EDTMP coated MOx, and c Comparison of ROS generation and cell viabilities in BEAS-2B cells exposed to uncoated and EDTMP coated MOx. The measurement of ion release and oxidative capability was described in the legend of Fig. 1. After 16 h exposure of BEAS-2B cells to $100 \mathrm{\mu g} / \mathrm{mL}$ MO suspensions, intracellular ROS generation was visualized by Mitosox staining. The cell viabilities were determined by MTS assay in BEAS-2B cells after $24 \mathrm{~h}$ incubation with $200 \mu \mathrm{g} / \mathrm{mL}$ MO suspensions. ${ }^{*} p<0.05$ compared to uncoated MOx

central metal atoms, which are shielded from interacting with ligands in biological environment such as protons, biomolecules, etc. Since EDTMP was reported to have strong binding affinity with heavy metal ions [30-32], this coating may be used for a broad spectrum of toxic MOx to provide stable inert surfaces.

\section{Extending EDTMP coating to other toxic MOx}

We further applied this coating to other MOx including $\mathrm{TiO}_{2}, \mathrm{Ni}_{2} \mathrm{O}_{3}, \mathrm{Co}_{3} \mathrm{O}_{4}$ and $\mathrm{CoO}$, and demonstrated that EDTMP coating could effectively reduce the ion shedding and oxidative stress on the surface of toxic MOx. As shown in Fig. $3 \mathrm{~b}$, after coating, there is less than $2 \%$ ion release for $\mathrm{Co}_{3} \mathrm{O}_{4}$ and $\mathrm{CoO}$ nanoparticles in acidic solution, while $\mathrm{Ni}_{2} \mathrm{O}_{3}$ and $\mathrm{CuO}$ particles only show
$<0.2 \%$ dissolution. The ion shedding from toxic $\mathrm{MOx}$ reduced $85-99 \%$ after EDTMP coating. The DCF result shows that the oxidation potentials of these $\mathrm{MOx}$ decrease $65-98 \%$, and almost get to background level after coating. Besides, we used Mitosox staining to visualize ROS production (red dots) in cells treated with MOx. Compared to the generation of massive red dots by $\mathrm{CuO}, \mathrm{Ni}_{2} \mathrm{O}_{3}, \mathrm{Co}_{3} \mathrm{O}_{4}$ and $\mathrm{CoO}$ particles, very limited red dots could be observed in cells treated with EDTMP coated MOx (Fig. 3c). The cytotoxicity results also show that EDTMP coating could completely eliminate the cytotoxicity of MOx in BEAS-2B and THP-1 cells (Fig. 3c and Additional file 6: Figure S5). In addition, we found EDTMP coating does not interfere in the cellular uptake mechanism (endocytosis) of MOx 
(Additional file 7: Figure S6). Although EDTMP coating shows a little interference on the cellular uptake levels of some MOx (Additional file 8: Figure S7), these inferences cannot explain the protective effects of EDTMP coating layer. These results suggested that the surface passivation rather than cellular uptake interference by EDTMP coating is responsible for the reduced cytotoxicity of all coated MOx, and EDTMP coating could be potentially used as a safe design approach for a broadspectrum of MOx.

\section{Validation of the protective effect of EDTMP coating in animals}

In order to further validate EDTMP coating in animals, mice were exposed to Quartz (positive $\mathrm{Ctrl}$ ), $\mathrm{CuO}, \mathrm{Co}_{3} \mathrm{O}_{4}$, EDTMP-CuO, EDTMP- $\mathrm{Co}_{3} \mathrm{O}_{4}$ and $\mathrm{TiO}_{2}$ nanoparticles by oropharyngeal aspiration because inhalation is one of the most common exposure route of MOx to humans. After $40 \mathrm{~h}$ exposure, the animals were sacrificed to collect BALF and lung tissues. The LDH and cytokine release in BALF were determined by LDH assay and ELISA, respectively. As shown in Fig. 4a, most of the inflammatory cells induced by uncoated $\mathrm{MOx}$ are neutrophils. $\mathrm{CuO}$ and $\mathrm{Co}_{3} \mathrm{O}_{4}$ induce significant release of LDH in BALF (Fig. 4b), indicating substantial tissue damage induced by MOx. In addition, both $\mathrm{CuO}$ and $\mathrm{Co}_{3} \mathrm{O}_{4}$ result in increased production of cytokines or chemokines including IL-6, MCP-1 and LIX. Compared with uncoated particles, EDTMP coating could significantly reduce the production of $\mathrm{LDH}$, IL-6, MCP-1 and LIX. H\&E staining also shows that $\mathrm{CuO}$ and $\mathrm{Co}_{3} \mathrm{O}_{4}$ can induce severe inflammation in animal lungs, while EDTMP coated particles have no inflammatory effects (Fig. 4c). Pristine $\mathrm{TiO}_{2}$, as a negative control, induces very limited hazard effects in animal lungs. All these animal results demonstrated that EDTMP coating could be used as an effective safe design approach for MOx in vivo.

\section{Discussion}

This study showed that surface reactivity including ion shedding and oxidative capacity is the key physicochemical property that is responsible for the toxicity of MOx. In order to reduce or eliminate the toxicity of MOx, we examined a series of coating molecules to passivate the surface of MOx and successfully identified EDTMP, which could provide the most inert surface for toxic MOx including $\mathrm{CuO}, \mathrm{Co}_{3} \mathrm{O}_{4}, \mathrm{Ni}_{2} \mathrm{O}_{3}$ and $\mathrm{CoO}$. EDTMP coated MOx showed limited toxicity in THP-1 and BEAS-2B cells. Moreover, this coating could significantly reduce the production of neutrophil counts, $\mathrm{LDH}, \mathrm{MCP}-$ 1 , LIX and IL-6 in BALF as well as inflammation responses in animal lungs exposed to MOx for $40 \mathrm{~h}$.

To justify the relevance of our toxicity test to pulmonary damage in humans, we have to consider real life exposure scenarios in the workplace. Although we were not able to include human exposures in this study, recent studies have shown that when the lung burden and state of nanoparticle dispersion are kept similar, short-term inhalation exposures in rodents could be evaluated by the pulmonary responses to bolus exposure (such as oropharyngeal instillation) [33, 34]. In order to extrapolate the doses used in our exposures to MOx exposure in human, we used reported data showing that the mean values of eight-hour average particulate concentrations measured during welding at the welders' breathing zone $(0.5 \mathrm{~m})$ could be as high as $11.3 \mathrm{mg} / \mathrm{m}^{3}$ [34]. In addition, $\mathrm{NIOSH}$ has proposed recommended limits of exposure as $1 \mathrm{mg} / \mathrm{m}^{3}$ for $\mathrm{CuO}$ fume, $2.4 \mathrm{mg} / \mathrm{m}^{3}$ for fine $\mathrm{TiO}_{2}$. Based on the calculation approach for nanomaterials being used at NIOSH [3537], we could estimate that a worker exposure of 1$11.3 \mathrm{mg} / \mathrm{m}^{3}$ MOx for $8 \mathrm{~h} /$ day over a five month time period over a 10-year working time could lead to a lung burden similar to a bolus exposure of $1-12 \mathrm{mg} / \mathrm{kg}$ in the mouse. This dose range is equivalent to $0.5-6 \mathrm{mg} / \mathrm{m}^{2}$ of $\mathrm{MOx}$ exposure in the mouse lung, assuming the alveolar epithelium surface area of $0.05 \mathrm{~m}^{2}$ and a body weight of $25 \mathrm{~g}$ [38]. Assuming that the in vitro MOx dose is homogeneously distributed in cell culture media $(100 \mu \mathrm{L} /$ well, 96 well plate) and the percentages of MOx settlement are higher than $70 \%$ [39], the in vitro cell exposure dose would be $1.6-16 \mu \mathrm{g} / \mathrm{mL}$. The in vivo dose used in this study is $2 \mathrm{mg} / \mathrm{kg}$, which has previously been shown to be on the steep part of the dose response curve for MOx and relevant to the airborne levels of MOx in workplace [13]. The doses used in cell experiments range from 0 to $200 \mu \mathrm{g} / \mathrm{mL}$, which is also comparable to the extrapolated in vitro doses $(1.6-16 \mu \mathrm{g} / \mathrm{mL})$. These estimates suggest that the MOx doses tested in cells and mice in this study are relevant to occupational exposures in humans. However, this in vitro dosage is only an estimation based on several assumptions, and more sensitive measurements and exposure models for MOx may be needed to better estimate the in vitro exposure dose [40].

MOx have been reported to elicit a series of adverse outcome pathways (AOPs) including ROS generation [5], mitochondrial damage [6], cytochrome $C$ release [7], DNA damage [8], inflammatory cytokine release [9-11], disruption of autophagic flux [11, 41], etc. Although the AOPs are largely influenced by cell types and their states of differentiation, the nano-bio interactions of MOx have been considered to play a major role. The physical, chemical or electronic transaction would take place between the surfaces of MOx and the surfaces of biological components at the nano-bio interface. Zhang et al. have proved that the band gap and Fermi energy level of MOx determine the overlap of $E_{c}$ levels of particles and the biological redox potential $[13,15]$. This allows electron transfer from the biological redox couples to the 


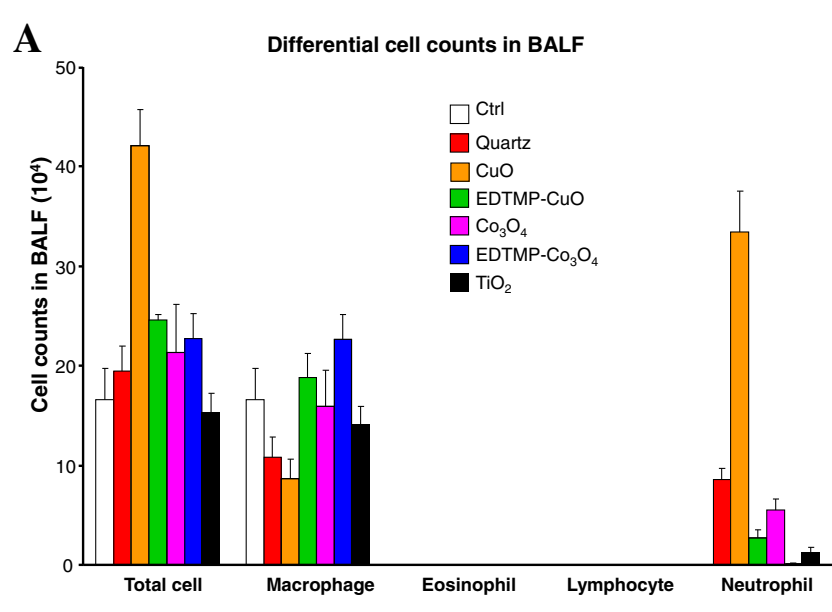

B
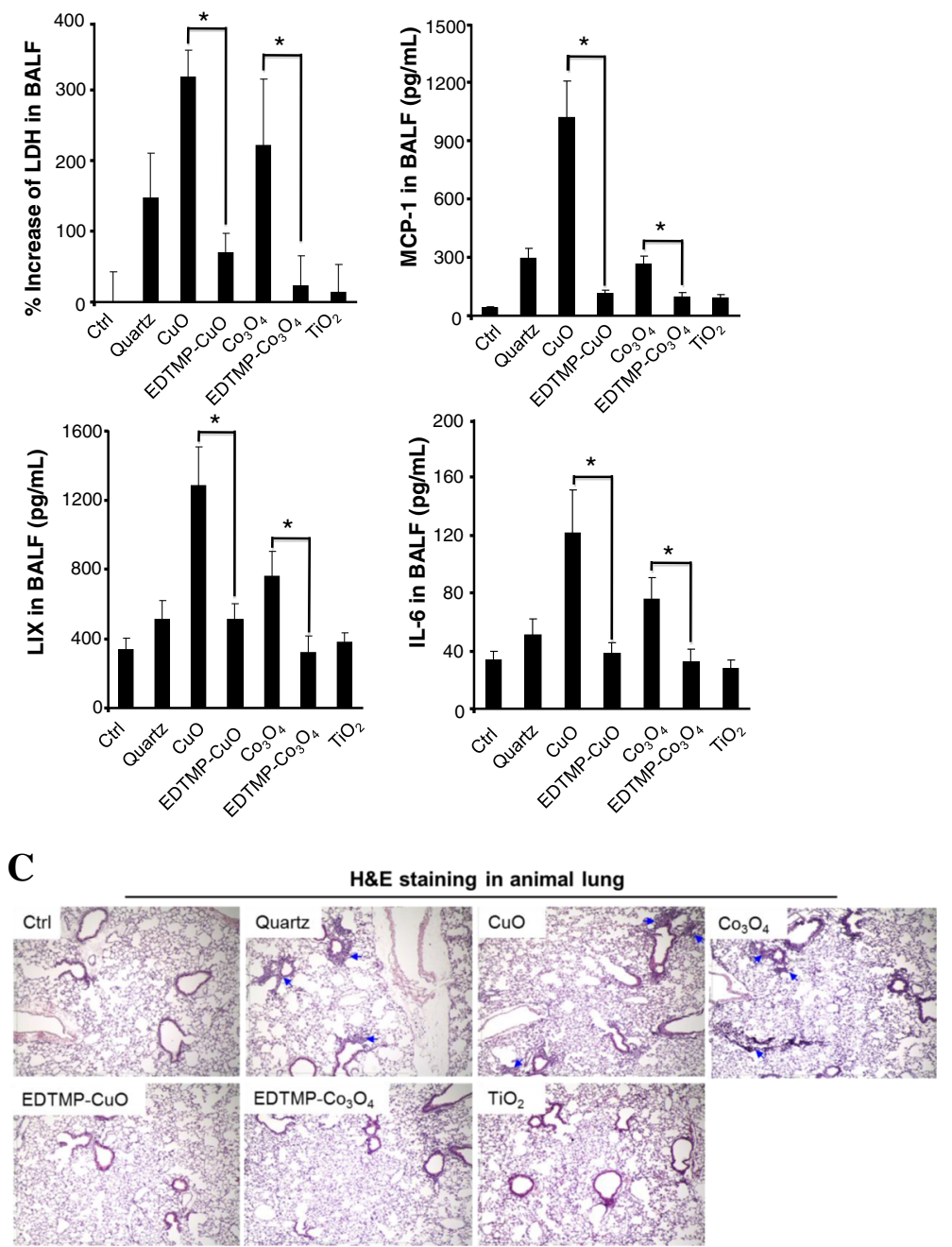

Fig. 4 Safety assessment of EDTMP coated MOx in animal lungs. a Differential cell counts in BALF, $\mathbf{b} L D H$ and cytokine release in BALF, $\mathbf{c} H \& E$ staining of lung sections from MO-exposed mice. $\mathrm{TiO}_{2}, \mathrm{CuO}, \mathrm{EDTMP}-\mathrm{CuO}, \mathrm{CO}_{3} \mathrm{O}_{4}$ or EDTMP- $\mathrm{CO}_{3} \mathrm{O}_{4}$ were oropharyngeally administrated at $2 \mathrm{mg} / \mathrm{kg}$ ( 6 mice in each group), while animals received $5 \mathrm{mg} / \mathrm{kg}$ quartz exposure were used as positive control. After $40 \mathrm{~h}$, animals were sacrificed to analyze LDH (upper left panel), MCP-1 (upper right panel), LIX (lower left panel) and IL-6 (lower right panel) production in BALF. * $p<0.05$ compared to uncoated MOX 
surface of MOx, causing disruption of cellular redox homeostasis and induction of oxidative stress. Our previous studies have showed that ion shedding from the surfaces of MOx could also lead to severe hazard effect by mitochondria-mediated apoptosis or stripping of phosphate groups from biomolecules [10, 42]. Thus, surface reactivity is the dominated physicochemical property of MOx, resulting in adverse biological outcomes.

The study of the relationship between the surface reactivity of MOx and their biological effects provides opportunities for safe design of MOx. Although some approaches including coating $[16,17]$, core-shell structure [18, 19], doping [20] and geometric control [21] have been used to reduce the hazard effects of MOx, there is lacking of a simple method for a broad spectrum of toxic MOx. In this study, we chose surface coating, and EDTMP was identified as the most effective coating agent to passivate MOx surfaces. MOx particles have high binding affinity with EDTMP because of the unique complexation of metal atoms on particle surfaces. The metal atoms could stably chelate with the organophosphate ligand in a hexadentate fashion, involving two nitrogen and four oxygen atoms. The interaction between the metal atoms on the surface of MOx and the biological components could be significantly shielded because the tetrahedral phosphonic groups of EDTMP limit the free space around the metal atoms. As a result, the EDTMP coating is very stable, even under acidic biological conditions. Since EDTMP has been reported as an effective chelate for a variety of heavy metal ions, including $\mathrm{Co}, \mathrm{Zn}$, $\mathrm{Cu}, \mathrm{Mn}$, etc. [30-32], EDTMP coating could be used as an effective safe design approach for a broad spectrum of high toxic MOx.

Beside of the reduction of hazard effects, a valuable safe-by-design strategy must not significantly interfere with the potential application value of the nanomaterial. Because of their advanced properties, nanomaterials have been applied in many fields. Some of their utilities (e.g. pigment, cosmetics, etc.) may lead to high exposure risk and threaten human health, while MOx in some of their applications (e.g. mechanical parts, electronic products, etc.) may have limited exposure to humans. Although it's hard to find a universal safe-bydesign strategy that has no interferences for all of their potential application values, it's possible to explore a safe design method that can reduce the hazard effects of nanomaterials during their applications with high exposure risk. In terms of the wide applications of MOx in pigments [43, 44], our EDTMP coating has negligible interferences in the visible light absorbance of $\mathrm{MOx}$ (380-780 nm), suggesting that our safe-by-design approach does not affect the applications of MOx in pigments.

\section{Conclusions}

In this communication, we developed an effective safe design method for toxic MOx through surface coating. We selected $\mathrm{CuO}, \mathrm{Ni}_{2} \mathrm{O}_{3}, \mathrm{CoO}$ and $\mathrm{Co}_{3} \mathrm{O}_{4}$ for the study, and they could induce toxicity by ion shedding or ROS generation on their surface. Among the coating agents, we successfully identified EDTMP to be the most effective in reducing ROS generation and dissolution, resulting in decreased cytotoxicity. This protection effect of EDTMP to MOx has been further validated in animal lungs. This EDTMP-based safe design approach has the potential to be applied to a broad-spectrum of MOx based nanoproducts, which will significantly reduce their hazard effects in humans, facilitate the safe and sustainable development of nanotechnology.

\section{Additional files}

Additional file 1: Table S1. Zeta potential and hydrodynamic size of uncoated and EDTMP coated MOx. (PDF 64 kb)

Additional file 2: Figure S1. Intracellular distribution of $\mathrm{MOx}$ by confocal imaging. THP-1 cells were exposed to $25 \mu \mathrm{g} / \mathrm{mL} \mathrm{TiO}{ }_{2}, \mathrm{CO}_{3} \mathrm{O}_{4}$ or $\mathrm{CuO}$ nanoparticle suspensions for $16 \mathrm{~h}$. Then the cells were stained with Hoechst 33342 and Alexa Fluor 594 labeled anti-LAMP1 to visualize the nuclei and lysosomes, respectively, by SP2 1P/FCS and Leica confocal SP2 MP-FLIM microscope. (PDF $158 \mathrm{~kb}$ )

Additional file 3: Figure S2. Assessment of cell viability in THP-1 cells exposed to MOx. THP-1 cells were exposed to MOx suspensions for $24 \mathrm{~h}$. The cell viability was tested by MTS (left panel) or ATP (right panel) assay by measuring the absorbance or luminescence on a SpectraMax M5 microplate spectrophotometer. (PDF 83 kb)

Additional file 4: Figure S3. Cell viabilities of PVP, citrate, EDTMP coated and uncoated CUO NPS. THP-1 or BEAS-2B cells were exposed to EDTMP, citrate, PVP coated and uncoated CuO NPs for $24 \mathrm{~h}$. The cell viability was tested by MTS assay. (PDF 83 kb)

Additional file 5: Figure S4. Characterization of $\mathrm{CuO}$ particles following EDTMP coating. A) TEM images of uncoated and coated $\mathrm{CuO}$ particles, B) FTIR spectra of uncoated and EDTMP-coated CuO as well as EDTMP by itself and C) XRD spectra of uncoated and coated particles. Both the coated and uncoated $\mathrm{CuO}$ particles show similar sphere shape with size at $10-20 \mathrm{~nm}$. The presence of an EDTMP coating is demonstrated by characteristic $P=O$ peaks. XRD analysis indicates that EDTMP coating do not change the crystal structure of CuO NPs. (PDF 272 kb)

Additional file 6: Figure S5. Viabilities of THP-1 cells exposed to uncoated and EDTMP coated MOx. After $24 \mathrm{~h}$ exposure of THP-1 cells $200 \mu \mathrm{g} / \mathrm{mL}$ MO suspensions, the cell viabilities were determined by MTS assay. (PDF $98 \mathrm{~kb}$ )

Additional file 7: Figure S6. Influence of EDTMP coating to the cellular uptake mechanism of MOx. BEAS-2B cells pretreated with $5 \mu \mathrm{g} / \mathrm{mL}$ cytochalasin D for $3 \mathrm{~h}$ were incubated with $50 \mu \mathrm{g} / \mathrm{mL}$ nanoparticles for an additional $6 \mathrm{~h}$. The cellular uptake levels of MOx were determined by ICP-OES. (PDF $124 \mathrm{~kb}$ )

Additional file 8: Figure S7. Cellular uptake levels of coated and uncoated MOx. THP-1 or BEAS-2B cells were treated with $50 \mu \mathrm{g} / \mathrm{mL}$ nanoparticles for $6 \mathrm{~h}$. After thorough washing, the cells were lysed to determine the protein concentrations as well as the metal elements. * $p<0.05$ compared to uncoated particles. (PDF $124 \mathrm{~kb}$ )

\section{Abbreviations}

AOPs: Adverse outcome pathways; BALF: bronchoalveolar lavage fluid; DCF: 2',7'-dichlorofluorescein; DLS: Dynamic light scattering;

EDTMP: Ethylenediamine tetra (methylene phosphonic acid); FTIR: Fourier 
transform infrared; H\&E: Haematoxylin/eosin; $\mathrm{H}_{2}$ DCFDA: 2',7'-dichlorodihydrofluorescein diacetate; ICP-OES: inductively coupled plasma optical emission spectrometry; LDH: lactate dehydrogenase; MOx: metal oxides; NPs: nanoparticles; PMA: phorbol 12-myristate acetate; PVP: poly(vinylpyrrolidone); ROS: reactive oxygen species; SD: standard deviation; TEM: Transmission electron microscopy

\section{Acknowledgements}

This work was supported by the grant from the National Natural Science Foundation of China (No. 31671032; 31570899), and a project funded by the Priority Academic Program Development of Jiangsu Higher Education Institutions (PAPD). R.L. is supported by the recruitment program of Global Youth Experts of China.

\section{Funding}

We thank the National Natural Science Foundation of China (No. 31671032; 31570899).

\section{Availability of data and materials}

The datasets analyzed during this study will be made available from the corresponding author upon a reasonable request.

\section{Authors' contribution}

$\mathrm{XC}$ and $\mathrm{AL}$ designed and performed most of the experiments; $\mathrm{ZJ}, \mathrm{CH}$ and $\mathrm{CHC}$ characterized the nanomaterials used in this study; XW and YPL performed the oropharyngeal instillation of nanomaterials into animal lungs as well as some animal experiments. The writing of the paper was led by RL and TX. All authors read and approved the final manuscript.

\section{Competing interests}

The authors declare that they have no competing interest.

\section{Consent for publication}

"Not applicable".

\section{Ethics approval}

All procedures performed on animals were approved by UCLA guidelines as well as the NIH Guide for the Care and Use of Laboratory Animals (DHEW78-23).

\section{Publisher's Note}

Springer Nature remains neutral with regard to jurisdictional claims in published maps and institutional affiliations.

\begin{abstract}
Author details
${ }^{1}$ Center for Genetic Epidemiology and Genomics, School of Public Health, Jiangsu Key Laboratory of Preventive and Translational Medicine for Geriatric Diseases, Medical College of Soochow University, Suzhou 215123, China. ${ }^{2}$ School for Radiological and Interdisciplinary Sciences (RAD-X), Collaborative Innovation Center of Radiation Medicine of Jiangsu Higher Education Institutions, Jiangsu Provincial Key Laboratory of Radiation Medicine and Protection, Soochow University, Suzhou 215123, China. ${ }^{3}$ Department of Medicine, University of California, Los Angeles, California 90095, USA. ${ }^{4}$ California NanoSystems Institute, University of California, Los Angeles, California 90095, USA. ${ }^{5}$ Department of Chemical and Biomolecular Engineering, University of California, Los Angeles, California 90095, USA. ${ }^{6}$ Department of Microbiology, Immunology, and Molecular Genetics, University of California, Los Angeles, California 90095, USA.
\end{abstract}

Received: 28 December 2016 Accepted: 10 April 2017 Published online: 21 April 2017

\section{References}

1. Li Y, Yu S, Yuan T, Yan M, Jiang Y. Rational design of metal oxide nanocomposite anodes for advanced lithium ion batteries. J Power Sources. 2015;282:1-8.

2. Rawat J, Ray S, Rao PVC, Choudary NV. Recent Developments of Nanomaterial Doped Paints for the Minimization of Biofouling in Submerged Structures. In: AlAhmed A, editor. Current Applications of Polymers and Nano Materials, vol. 657. 2010. p. 75-82.

3. Zhao Z, Tian J, Sang Y, Cabot A, Liu H. Structure, Synthesis, and Applications of TiO2 Nanobelts. Adv Mater. 2015;27(16):2557-82.
4. Moore MN. Do nanoparticles present ecotoxicological risks for the health of the aquatic environment? Environ Int. 2006;32(8):967-76.

5. Jing X, Park JH, Peters TM, Thorne PS. Toxicity of copper oxide nanoparticles in lung epithelial cells exposed at the air-liquid interface compared with in vivo assessment. Toxicol Vitro. 2015;29(3):502-11.

6. Yu K-N, Yoon T-J, Minai-Tehrani A, Kim J-E, Park SJ, Jeong MS, et al. Zinc oxide nanoparticle induced autophagic cell death and mitochondrial damage via reactive oxygen species generation. Toxicol Vitro. 2013;27(4):1187-95.

7. Wang Y, Yang F, Zhang HX, Zi XY, Pan XH, Chen F, et al. Cuprous oxide nanoparticles inhibit the growth and metastasis of melanoma by targeting mitochondria. Cell Death Dis. 2013;4, e783.

8. Moller P, Jensen DM, Christophersen DV, Kermanizadeh A, Jacobsen NR, Hemmingsen JG, et al. Measurement of Oxidative Damage to DNA in Nanomaterial Exposed Cells and Animals. Environ Mol Mutagen. 2015; 56(2):97-110.

9. Dandley EC, Taylor AJ, Duke KS, Ihrie MD, Shipkowski KA, Parsons GN, et al. Atomic layer deposition coating of carbon nanotubes with zinc oxide causes acute phase immune responses in human monocytes in vitro and in mice after pulmonary exposure. Part Fibre Toxicol. 2016;13:29.

10. Li R, Ji Z, Chang CH, Dunphy DR, Cai X, Meng H, et al. Surface Interactions with Compartmentalized Cellular Phosphates Explain Rare Earth Oxide Nanoparticle Hazard and Provide Opportunities for Safer Design. ACS Nano. 2014;8(2):1771-83.

11. Li R, Ji Z, Qin H, Kang X, Sun B, Wang M, et al. Interference in Autophagosome Fusion by Rare Earth Nanoparticles Disrupts Autophagic Flux and Regulation of an Interleukin-1 beta Producing Inflammasome. ACS Nano. 2014;8(10):10280-92.

12. Semisch A, Ohle J, Witt B, Hartwig A. Cytotoxicity and genotoxicity of nano - and microparticulate copper oxide: role of solubility and intracellular bioavailability. Part Fibre Toxicol. 2014;11:10.

13. Zhang H, Ji Z, Xia T, Meng H, Low-Kam C, Liu R, et al. Use of Metal Oxide Nanoparticle Band Gap To Develop a Predictive Paradigm for Oxidative Stress and Acute Pulmonary Inflammation. ACS Nano. 2012;6(5):4349-68.

14. Stern ST, Adiseshaiah PP, Crist RM. Autophagy and lysosomal dysfunction as emerging mechanisms of nanomaterial toxicity. Part Fibre Toxicol. 2012;9:20.

15. Zhang H, Pokhrel S, Ji Z, Meng H, Wang X, Lin S, et al. PdO Doping Tunes BandGap Energy Levels as Well as Oxidative Stress Responses to a Co3O4 p-Type Semiconductor in Cells and the Lung. J Am Chem Soc. 2014;136(17):6406-20.

16. Osmond-McLeod MJ, Osmond RIW, Oytam Y, McCall MJ, Feltis B, MackaySim A, et al. Surface coatings of $\mathrm{ZnO}$ nanoparticles mitigate differentially a host of transcriptional, protein and signalling responses in primary human olfactory cells. Part Fibre Toxicol. 2013;10:54

17. Chanana M, Gil PR, Correa-Duarte MA, Liz-Marzan LM, Parak WJ. Physicochemical Properties of Protein-Coated Gold Nanoparticles in Biological Fluids and Cells before and after Proteolytic Digestion. Angew Chem-Int Edit. 2013:52(15):4179-83.

18. Davidson DC, Derk R, He X, Stueckle TA, Cohen J, Pirela SV, et al. Direct stimulation of human fibroblasts by $\mathrm{nCeO} 2$ in vitro is attenuated with an amorphous silica coating. Part Fibre Toxicol. 2016;13:23.

19. Cheong S, Ferguson P, Feindel KW, Hermans IF, Callaghan PT, Meyer C, et al. Simple Synthesis and Functionalization of Iron Nanoparticles for Magnetic Resonance Imaging. Angew Chem-Int Edit. 2011;50(18):4206-9.

20. George S, Pokhrel S, Xia T, Gilbert B, Ji Z, Schowalter M, et al. Use of a Rapid Cytotoxicity Screening Approach To Engineer a Safer Zinc Oxide Nanoparticle through Iron Doping. ACS Nano. 2010;4(1):15-29.

21. Ji Z, Wang $X$, Zhang $H$, Lin S, Meng H, Sun B, et al. Designed Synthesis of $\mathrm{CeO} 2$ Nanorods and Nanowires for Studying Toxicological Effects of High Aspect Ratio Nanomaterials. ACS Nano. 2012;6(6):5366-80.

22. Wang X, Xia T, Duch MC, Ji ZX, Zhang HY, Li RB, et al. Pluronic F108 Coating Decreases the Lung Fibrosis Potential of Multiwall Carbon Nanotubes by Reducing Lysosomal Injury. Nano Lett. 2012;12(6):3050-61.

23. Wang X, Duch MC, Mansukhani N, Ji Z, Liao Y-P, Wang M, et al. Use of a Pro-Fibrogenic Mechanism-Based Predictive Toxicological Approach for Tiered Testing and Decision Analysis of Carbonaceous Nanomaterials. ACS Nano. 2015:9(3):3032-43.

24. Wang X, Mansukhani ND, Guiney LM, Ji Z, Chang CH, Wang M, et al. Differences in the Toxicological Potential of 2D versus Aggregated Molybdenum Disulfide in the Lung. Small. 2015;11(38):5079-87.

25. Marques MRC, Loebenberg R, Almukainzi M. Simulated Biological Fluids with Possible Application in Dissolution Testing. Dissolut Technol. 2011;18(3):15-28. 
26. Cho W-S, Duffin R, Bradley M, Megson IL, MacNee W, Lee JK, et al. Predictive value of in vitro assays depends on the mechanism of toxicity of metal oxide nanoparticles. Part Fibre Toxicol. 2013;10:55.

27. Panas A, Marquardt C, Nalcaci O, Bockhorn H, Baumann W, Paur HR, et al. Screening of different metal oxide nanoparticles reveals selective toxicity and inflammatory potential of silica nanoparticles in lung epithelial cells and macrophages. Nanotoxicology. 2013;7(3):259-73.

28. Wang $Y$, Zi X-Y, Su J, Zhang H-X, Zhang X-R, Zhu H-Y, et al. Cuprous oxide nanoparticles selectively induce apoptosis of tumor cells. Int J Nanomed. 2012;7:2641-52.

29. Liu X, Li Z, Zhang Q, Li F, Kong T. CuO nanowires prepared via a facile solution route and their photocatalytic property. Mater Lett. 2012;72:49-52.

30. Li R, Ji Z, Dong J, Chang CH, Wang X, Sun B, et al. Enhancing the Imaging and Biosafety of Upconversion Nanoparticles through Phosphonate Coating. ACS Nano. 2015:9(3):3293-306.

31. Motekaitis RJ, Murase I, Martell AE. Equilibria of ethylenediamine-N, N, N', N'-tetrakis(methylenephosphonic) acid with $\mathrm{Cu}(\mathrm{II}), \mathrm{Ni}(\mathrm{II}), \mathrm{Co}(\mathrm{II}), \mathrm{Zn}(\mathrm{II}), \mathrm{Mg}(\mathrm{II})$ $\mathrm{Ca}(\mathrm{II})$, and Fe(III) ions in aqueous-solution. Inorg Chem. 1976;15(9):2303-6.

32. Westerback SJ, Martell AE. Ethylene-diamine-tetra(methylene-phosphonic) acid. Nature. 1956;178(4528):321-2.

33. Kuempel ED, Castranova V, Geraci CL, Schulte PA. Development of riskbased nanomaterial groups for occupational exposure control. J Nanopart Res. 2012;14:1029.

34. Balkhyour MA, Goknil MK. Total Fume and Metal Concentrations during Welding in Selected Factories in Jeddah, Saudi Arabia. Int J Environ Res Public Health. 2010:7(7):2978-87.

35. Castranova V, Schulte PA, Zumwalde RD. Occupational Nanosafety Considerations for Carbon Nanotubes and Carbon Nanofibers. Accounts Chem Res. 2013;46(3):642-9.

36. NIOSH: Current Intelligence Bulletin 65: Occupational Exposure to Carbon Nanotubes and Nanofibers. https://www.cdc.gov/niosh/docs/2013-145/pdfs/ 2013-145.pdf. (Accessed Apr 2013).

37. Porter DW, Hubbs AF, Mercer RR, Wu N, Wolfarth MG, Sriram K, et al. Mouse pulmonary dose- and time course-responses induced by exposure to multiwalled carbon nanotubes. Toxicology. 2010;269:136-47.

38. Stone KC, Mercer RR, Gehr P, Stockstill B, Crapo JD. Allometric relationships of cell numbers and size in the mammalian lung. Am J Respir Cell Mol Biol. 1992; $6(2): 235-43$

39. Liu R, Liu HH, Ji ZX, Chang CH, Xia T, Nel AE, et al. Evaluation of Toxicity Ranking for Metal Oxide Nanoparticles via an in Vitro Dosimetry Model. ACS Nano. 2015;9(9):9303-13.

40. Hinderliter PM, Minard KR, Orr G, Chrisler WB, Thrall BD, Pounds JG, et al. ISDD: A computational model of particle sedimentation, diffusion and target cell dosimetry for in vitro toxicity studies. Part Fibre Toxicol. 2010;7:36.

41. Yu L, Lu Y, Man N, Yu SH, Wen LP. Rare Earth Oxide Nanocrystals Induce Autophagy in HeLa Cells. Small. 2009:5(24):2784-7.

42. Xia T, Kovochich M, Liong M, Maedler L, Gilbert B, Shi H, et al. Comparison of the Mechanism of Toxicity of Zinc Oxide and Cerium Oxide Nanoparticles Based on Dissolution and Oxidative Stress Properties. ACS Nano. 2008:2(10):2121-34.

43. Gao Q, Wu X, Fan Y, Zhou X. Low temperature synthesis and characterization of rutile TiO2-coated mica-titania pigments. Dyes Pigment. 2012;95(3):534-9.

44. Sangeetha S, Basha R, Sreeram KJ, Sangilimuthu SN, Nair BU. Functional pigments from chromium(III) oxide nanoparticles. Dyes Pigment. 2012;94(3):548-52.

\section{Submit your next manuscript to BioMed Central and we will help you at every step:}

- We accept pre-submission inquiries

- Our selector tool helps you to find the most relevant journal

- We provide round the clock customer support

- Convenient online submission

- Thorough peer review

- Inclusion in PubMed and all major indexing services

- Maximum visibility for your research

Submit your manuscript at www.biomedcentral.com/submit
Biomed Central 